\title{
Telehealth and eHealth in nurse practitioner training: current perspectives
}

This article was published in the following Dove Press journal:

Advances in Medical Education and Practice

26 June 2017

Number of times this article has been viewed

\section{Carolyn M Rutledge' \\ Karen Kott ${ }^{2}$ \\ Patty A Schweickert ${ }^{3}$ \\ Rebecca Poston' \\ Christianne Fowler \\ Tina S Haney'}

'College of Health Sciences, School of Nursing, ${ }^{2}$ College of Health Sciences, School of Physical Therapy, Old Dominion University, Norfolk, ${ }^{3}$ Department of Neuroradiology, University of Virginia, Charlottesville, VA, USA
Correspondence: Carolyn M Rutledge Old Dominion University, Health Sciences Building, School of Nursing, Hampton Boulevard, Norfolk, Virginia 23529, USA

Email crutledg@odu.edu

\begin{abstract}
Telehealth is becoming a vital process for providing access to cost-effective quality care to patients at a distance. As such, it is important for nurse practitioners, often the primary providers for rural and disadvantaged populations, to develop the knowledge, skills, and attitudes needed to utilize telehealth technologies in practice. In reviewing the literature, very little information was found on programs that addressed nurse practitioner training in telehealth. This article provides an overview of both the topics and the techniques that have been utilized for training nurse practitioners and nurse practitioner students in the delivery of care utilizing telehealth. Specifically, this article focuses on topics including 1) defining telehealth, 2) telehealth etiquette, 3) interprofessional collaboration, 4) regulations, 5) reimbursement, 6) security/ Health Insurance Portability and Accountability Act (HIPAA), 7) ethical practice in telehealth, and 8) satisfaction of patients and providers. A multimodal approach based on a review of the literature is presented for providing the training: 1) didactics, 2) simulations including standardized patient encounters, 3) practice immersions, and 4) telehealth projects. Studies found that training using the multimodal approach allowed the students to develop comfort, knowledge, and skills needed to embrace the utilization of telehealth in health care.
\end{abstract}

Keywords: telehealth, nurse practitioner education, telemedicine, simulation, health care

\section{Introduction}

Health care systems continue to struggle to provide access to cost-effective quality care. The dramatic changes in health care reflected by increasing patients with multiple chronic diseases, health care workforce shortages, mandates to decrease costs, and infusion of technology make it necessary for nurse practitioners to embrace telehealth. ${ }^{1}$ The use of telehealth technology presents new opportunities for addressing these challenges by increasing patient access to care and decreasing costs, while improving desired care outcomes. ${ }^{2}$

For nurse practitioners to address health care of the future, advanced knowledge and skills in the use and application of telehealth technologies in practice are becoming essential. Preparing nurse practitioners to utilize telehealth technology requires specific and dedicated didactic and experiential telehealth education incorporated within existing curricula. It is important that educational programs focus on the understanding of telehealth and its application as well as skills development. Based on a comprehensive review of the literature, this article provides a multimodal framework for preparing nurse practitioners to utilize and champion the use of telehealth within the complex health care environment. 


\section{Literature search and study selection}

A systematic literature search was conducted in MEDLINE, EMBASE, PEDro, Scopus, Cochrane Central Register of Controlled Trials, CINAHL, and PsycINFO to identify current evidence and strategies for preparing providers in the utilization of telehealth within health care. The search was limited to peer-reviewed journals that were published in English in the US. Search keywords included telehealth, mhealth, eHealth, telemedicine, systematic reviews, education, and nurse practitioner. The review focused on educational programs in health care that focused on eHealth, telehealth, and telemedicine. Eighty articles were initially reviewed. Articles that focused on the care of patients using telehealth were removed from the review as the focus of this article was on education. Articles that either described programs developed to educate students in telehealth and eHealth or provided content that should be included in such programs were chosen.

\section{Gaps in the literature}

Literature related to preparing nurse practitioners to utilize telehealth for practice is limited. Much of the literature supports the need for educational programs in telehealth and documents content that should be provided; however, there are very few articles that describe the educational process for nurse practitioners. Many of the programs that are provided focus on the education of medical students or mental health providers. ${ }^{3-5}$ One review found only 11 studies that reported the results of educational programs designed to deliver telehealth training. Five of the studies described short continuing education programs $\mathrm{s}^{3-7}$ and only six described formal university programs $\mathrm{s}^{8-13}$ with three being with nurse practitioners. ${ }^{9,11,12}$ Compared to other aspects of telehealth research (i.e., feasibility, effectiveness, economics, and satisfaction), literature related to education and training in telehealth has remained scant. ${ }^{14}$ This may be due to many providers being unacquainted with telehealth or perhaps a lack of interest in the field, secondary to this limited experience. ${ }^{15,16}$ One study found that $77 \%$ of faculty surveyed identified a need for training in telehealth. ${ }^{15}$ The cost of starting a telehealth program was also identified as a barrier to programmatic implementation. ${ }^{15}$ Ali et $a{ }^{15}$ found that the programs that did utilize equipment as a tool for teaching telehealth were only able to do so with funding from a Health Resources and Services Administration (HRSA) grant.

One major gap identified in the literature is the incorporation of the human factors content related to telehealth (communication, empathy, and telehealth etiquette). ${ }^{17,18}$ While studies do exist related to phone etiquette and phone communication between provider and patients, ${ }^{19,20}$ government regulations and the American Telehealth Association do not classify telephone communication with patients as telehealth. ${ }^{21,22}$ Providers who had been using telehealth for several years discussed the "filter" of technology and how they were uncomfortable with the human factors necessary to conduct a telehealth visit. ${ }^{23}$

This review suggests that there is a shortage of health professional programs that actually integrate training in telehealth within their health care curriculum. Most of the journal articles on telehealth tend to focus on didactic content rather than hands-on experience or clinical placements. Due to the paucity of articles on the training of nurse practitioners, this article will provide an overview of first the topics that should be covered and then the techniques that have been used in telehealth education.

\section{Topics}

Telehealth programs have been used to provide content that focuses on 1) defining telehealth, 2) telehealth etiquette, 3) interprofessional collaboration, 4) regulations, 5) reimbursement, 6) security/Health Insurance Portability and Accountability Act (HIPAA), 7) ethical practice in telehealth, and 8) satisfaction. ${ }^{14,15,17,23-25}$ The following sections address recommended topics that programs might consider addressing when training nurse practitioners in telehealth.

\section{Defining telehealth}

Technology has been applied to health care in so many diverse ways that it is not surprising that there is great confusion as to what terms such as telemedicine and telehealth mean and how they are used in health care. Thus, educational programs might begin with a clear understanding of what constitutes telehealth and how it differs from telemedicine. While some organizations such as the American Telemedicine Association (ATA) use telehealth and telemedicine interchangeably, ${ }^{26}$ many definitions discern a difference between telehealth and telemedicine. There have been more than 100 definitions of telemedicine in the literature over the past 10 years, suggesting that clarification for practitioners is needed. ${ }^{27}$ The HRSA $^{28}$ defines telehealth as the use of technology in care delivery, health information, and remote health education. Telehealth is therefore the use of electronic information, devices, and telecommunication technology to provide direct patient care, remote patient monitoring, and education at a distance. Telephone, audio-only, text messaging, 
fax, and email communication are not considered telehealth technologies. ${ }^{21,22}$ Telehealth has been called a "disruptive technology" 29 in that it may either replace or supplement the traditional face-to-face patient-provider encounter.

By contrast, telemedicine, a part of telehealth, generally denotes patient care delivery by way of the virtual clinic visit or specialty consultation. According to the World Health Services Organization, ${ }^{30}$ telemedicine is

the delivery of health care services, where distance is a critical factor, by all health care professionals using information and communication technologies for the exchange of valid information, for diagnosis, treatment and prevention of disease and injuries, research and evaluation, and for the continuing education of health care providers, all in the interest of advancing the health of individuals and their communities.

For the purpose of this article, telehealth includes all uses of technology to communicate with patients and/or practitioners regarding health and health care delivery, monitoring, and/ or education. Telemedicine is part of telehealth but involves virtual medical consultations (patient-providers or providers-providers), virtual clinic visits, remote monitoring, and teletransfer of diagnostic imaging. Figure 1 provides a detailed outline of telehealth and its connection to telemedicine.

Amid the complexity of technology in general, there are only two basic types of technology used in telehealth:
1) real-time videoconferencing and 2) store-and-forward technologies. The development of Integrated Services Digital Network (ISDN) technology enabled transfer of both video and voice connections at the same time over one line, making live video conferencing possible. ${ }^{31}$ Videoconferencing allows patients and providers at different sites to see and talk with one another in real time using computers, cameras, TVs, microphones, software, and computer networks. ${ }^{32}$ Today's videoconferencing technology in health care enables two or more people to connect for consultation and care, patient management and monitoring, and education across the state or across the world.

Alternatively, telehealth store and forward technologies enable remote transfer of patient diagnostic and physiologic data from one site to another for evaluation and interpretation. ${ }^{30}$ With store and forward technologies, data are transmitted from a source and are "stored" at a transitional or intermediary station or "node", usually a server, before being sent, or "forwarded" to the intended destination. ${ }^{33}$ Store and forward data are used when it is not imperative that the patient requires face-to-face interaction to achieve care. Common store and forward data include radiology and medical imaging, retinal photos, physiologic data (blood pressure, blood glucose levels, oxygen saturation levels, and weight), electrocardiograms, patient education and symptom survey data, dermatology images, pathology images, and wound images. ${ }^{34}$

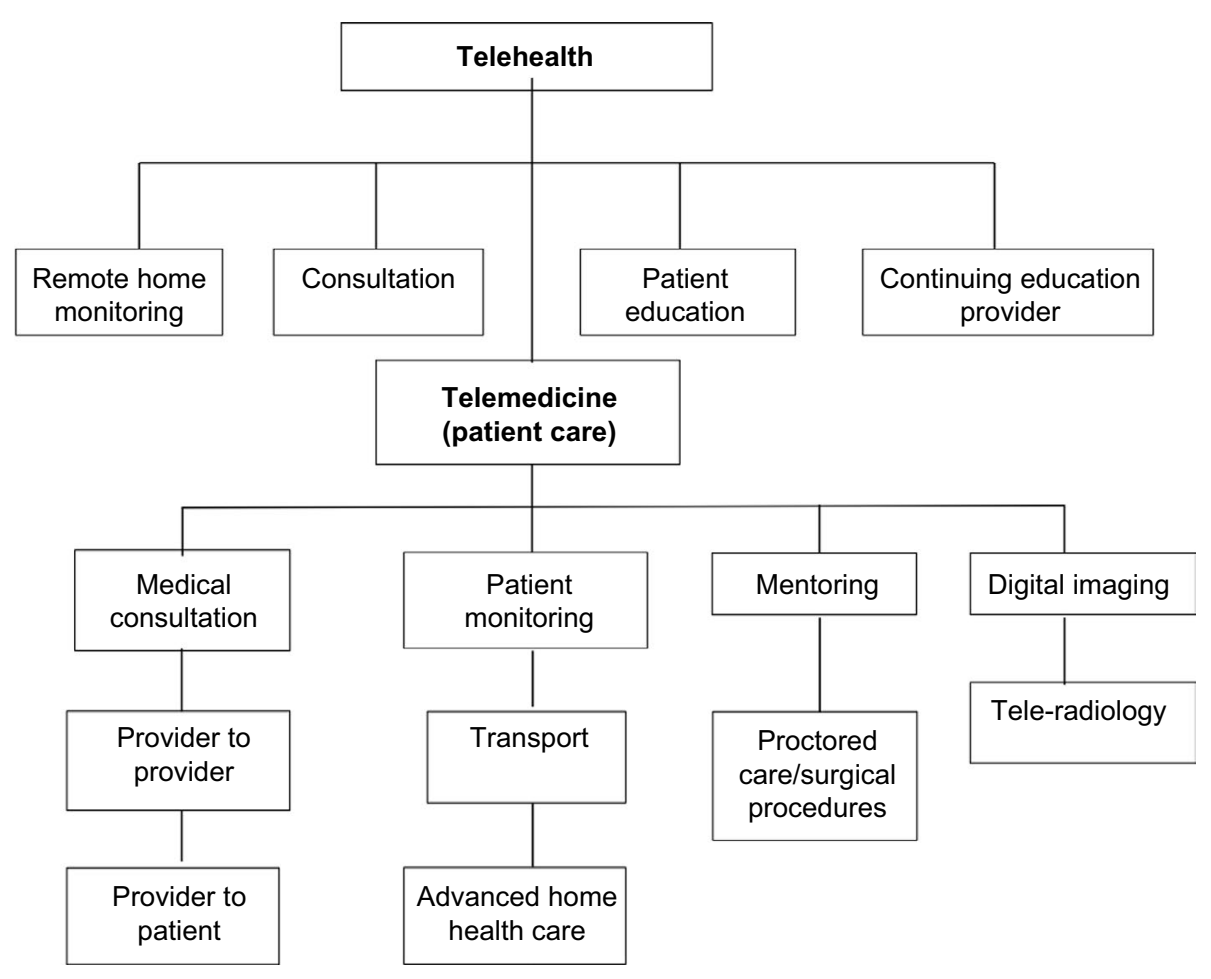

Figure I Diagram of telehealth and telemedicine. 
Remote home monitoring, a form of store and forward technology, allows for more frequent patient monitoring and trending of physiologic data, which is especially promising for improving chronic disease management. ${ }^{35} \mathrm{~A}$ remote home monitoring telemedicine system is installed in the patient's home and used to transmit data to a provider site. Ideally, after the information is collected and evaluated, the provider/nurse practitioner and the patient engage in a live videoconferencing session, where a clinical consultation can take place virtually as if it were face to face. ${ }^{36,37}$

\section{Telehealth etiquette}

An important aspect of the telehealth encounter that must be included in health care professionals' education is telehealth etiquette. Telehealth etiquette includes the unique behaviors necessary to conduct an effective telehealth visit. ${ }^{15,17}$ These behaviors are similar, yet different from previously learned behaviors necessary to conduct either a traditional in-person visit or a telephone consultation. ${ }^{19}$ Telehealth etiquette includes proper camera positioning, elimination of office or clinic noise, the removal of personal objects located within view of the camera, and even the clothing choice made by the provider. ${ }^{17}$ Bright or busy clothing patterns can distract from a telehealth encounter. Traditional communication skills must also be adjusted for this type of visit. Students must be taught the subtleties of eye contact during a telehealth visit. Eye contact is made with the client by looking at the camera, not the client's face on the screen. Looking down or taking notes can be perceived as disinterest or distraction. ${ }^{17,23}$ While empathy can be conveyed during a telehealth visit, it must be carefully constructed. Students must be taught to look and lean into the camera and to nod their head to encourage their client. Rather than using touch, students must be taught to choose the words that they use with their clients carefully to display empathy. ${ }^{17,23,38}$ When students are adequately prepared to communicate using proper telehealth etiquette, they are better assured that they will have a successful visit. Strategies used to assist students in learning about telehealth etiquette include didactic lectures and visual examples as found in videoed encounters of poor telehealth interactions. ${ }^{39}$

\section{Interprofessional collaboration}

Interprofessional collaboration and learning how to accomplish it is now a mainstay of health profession education. Most of the professional organizations representing healthrelated professions have a mandate to include interprofessional education into their training programs. ${ }^{40}$ However, preparing students to collaborate through solely face-to-face encounters is not adequate for the nurse practitioners who will be providing care in rural and underserved areas where many professions do not reside. In addition, hierarchical models must be minimized if interprofessional collaboration is to be effective. Telehealth can serve as a tool to allow nurse practitioners and their patients to gain access to other professions at a distance as well as serving as an equalizer related to professional roles. Educational programs have been developed using didactic lectures and standardized patient experiences as well as intraprofessional projects to successfully teach interprofessional and intraprofessional collaboration using telehealth. ${ }^{41,42}$ These telehealth programs demonstrate effective collaboration in circumstances that would otherwise not be possible.

\section{Regulations}

Despite decades of research that highlights the positive impact that telehealth can have on patient outcomes and patient satisfaction, providers still face many obstacles when attempting to integrate telehealth into their practice. ${ }^{43}$ State laws and regulations that govern provider practice along with health insurance reimbursement rules for telehealth vary widely and often hinder the use of telehealth in certain practice settings. Thus, it is imperative that providers understand the regulations that impact their specific practice. In a report from the ATA ${ }^{43}$ comparing physician practice standards and licensure for telemedicine by state, barriers to telemedicine implementation were identified as 1) limiting definitions of physician-patient encounters, 2) requirements related to the presence of a telepresenter on-site during telemedicine encounters, 3) additional requirements of patient informed consent, 4) limited licensure portability/reciprocity across state lines, and 5) limitations related to internet prescribing. ${ }^{43}$ Nine states (Louisiana, Maine, Minnesota, Nevada, New Mexico, Ohio, Oregon, Tennessee, and Texas) currently require a special telehealth, conditional or special purpose license for providers to practice telemedicine across state lines. ${ }^{43}$ Washington DC, Maryland, New York, and Virginia have licensure reciprocity from bordering states, while 17 states have adopted the Federation of State Medical Boards (FSMB) Interstate Medical Licensure Compact to facilitate expedited out-of-state licensure for physicians wishing to practice telehealth across state lines. This promotes portability of licensure in inclusive states which follows the registered nurse licensure compact that has been adopted by 25 states. ${ }^{44,45}$ State regulations can require physicians practicing medicine across state lines to have a license in every state where their patients may be located. 
Regulations governing the practice of advanced practice nurses are often addressed by both the Board of Medicine and the Board of Nursing and vary widely from state to state. ${ }^{44}$ In some states, nurse practitioners do not practice independently but are required to have established practice agreements with supervising or collaborating physicians. Supervision of Advanced Practice Nurses by collaborating physicians can be accomplished via telehealth in some states but not all. ${ }^{44}$ As training is developed for nurse practitioners, there must be a focus on the regulations that will impact their utilization of telehealth.

\section{Reimbursement}

Telehealth technologies have reached a tipping point due to decreased cost of technology, adoption of standards-based operations, greater movement to the desktop and handheld devices, and simplification of processes. As a result, telehealth is incorporated into health care and health care delivery at an ever increasing rate. Telehealth has great potential as a tool in health care to help decrease costs, having the greatest effect in chronic disease management. ${ }^{46-48}$ Thus, it is important to not only educate nurse practitioners on the use of telehealth but also understand how the cost of telehealth is regulated.

One of the most important issues regarding the use of telehealth in practice is insurance coverage and provider reimbursement. Coverage for telehealth services in the US is addressed by federal and state laws and regulations. Nearly all state Medicaid programs reimburse for some form of telehealth services with 48 states providing reimbursement for telehealth services delivered via live video, 12 states allowing reimbursement for store-and-forward telehealth services, 19 states providing reimbursement for remote patient monitoring, and 7 states providing reimbursement for live video, store-and-forward, and patient monitoring telehealth services ${ }^{45}$ Medicare reimburses providers for live videoconferencing consults and visits, some store-and-forward services, and some remote monitoring for chronic diseases. ${ }^{29}$

There are three areas of requirements for reimbursement for telehealth services in the Medicare program. These include originating site, providers, and telehealth services. For coverage, the patient must be at the originating site (defined as the office of the practitioner, critical access hospitals, rural health clinics, skilled nursing facility, community mental health center, federally qualified health center, hospitals, or renal dialysis units). Unfortunately, the originating site cannot be the patient's home. In addition, originating sites must be in a designated rural health professional shortage areas or other specified area. Practitioners delivering care must also have privileges at the remote location where they are connecting for services. These barriers restrict the delivery of telehealth. ${ }^{49}$

States have the most control over laws and regulations for telehealth reimbursement and insurance coverage as they control the ability to pass legislation to allow or deny coverage. Almost all states, including the District of Columbia, include some coverage for telehealth in their Medicaid programs. A majority of states also have telehealth laws that require private payers to cover telehealth services. On the private payer side, 21 states have some form of legislation that addresses reimbursement for telehealth services for private payers. ${ }^{45}$

An important aspect of this coverage is whether there is parity in coverage. Parity allows for telehealth services to be covered at the same rates as those of face-to-face services. Opponents suggest that since telehealth can decrease costs of care it should be reimbursed at a lesser rate. However, proponents support equal coverage as incentives to use telehealth rather than face to face to get the higher reimbursements. Therefore, it is essential that nurses are familiar with the telehealth rules and regulation that govern their state to fully participate in nursing telehealth practice. ${ }^{50}$

\section{Security/HIPAA}

Ethical issues related to telehealth such as security, confidentiality, and patient information are paramount; most programs clearly address this content. ${ }^{16}$ The HIPAA of 1996 established guidelines for electronic health transactions, national identifiers for providers, and security and privacy of health data. ${ }^{50}$ The regulatory guidelines for privacy and confidentiality covered by HIPAA govern provider practice in all settings including telehealth encounters. Beyond safeguarding the privacy and confidentiality of private-protected personal health information (PHI), telehealth providers are responsible for ensuring that the "space" or environment where the encounter takes place is secure at both the originating location and the distant site and that the transmission between the originating site and distant site is secure. This necessitates proper encryption of protected patient data and appropriate HIPAA agreements with all technical personnel. ${ }^{50}$ Penalties for HIPAA infractions or violations can include fines up to $\$ 50,000$ per violation, criminal charges, and civil penalties. ${ }^{50}$

\section{Ethical practice in telehealth}

Telehealth practice is governed by the same Codes of Ethics for health care professionals as traditional face to face/same 
place encounters, yet the intricacies of providing care via this modality can trigger interesting ethical challenges for providers. Mehta ${ }^{51}$ outlines four potential ethical "pitfalls" related to telehealth implementation: erosion of the provider/patient relationship, threats to patient privacy, forcing one-size-fitsall implementations, and the temptation to assume that the new technology must be effective. Issues related to patient privacy, confidentiality, and security are addressed earlier, but exploring other areas of concern such as the erosion of the patient/provider relationship is paramount to a balanced and comprehensive advanced practice nursing curriculum. Ensuring that advanced practice nurses possess the moral sensitivity to identify ethical issues in care regardless of the structure and format of the interaction is an important step in advanced practice nursing education.

Providers have also voiced concern about the potential for patients to "shop" for providers and abuse the system in search of practitioners who will provide expedient care and desired prescriptions. ${ }^{52}$ Exploring how this is achieved within the ethical and legal landscapes that vary from state to state requires close review and understanding of the laws and regulations that govern provider scope of practice and the practice of telehealth. Kaplan and Litewka ${ }^{53}$ call for providers to thoughtfully explore the ethical issues of informed consent, autonomy, and empowerment within the context of an exploding technological shift toward telehealth and ehealth modalities. Thoughtful examination of what these cornerstone ethical concepts mean in the context of telehealth is an important part of the ethical trainings of nurse practitioners.

\section{Satisfaction with telehealth}

Of high importance in education is the need to increase the student's positive attitudes toward the topics presented, and telehealth is no exception. In fact, students are often resistant to engaging in telehealth activities stating that they will never use it or that their patients will not like it. Data must be presented to students on the importance of having an open mind toward telehealth. One approach is to present data on patient and provider acceptance.

Generally, the overall satisfaction levels for services delivered via telehealth have been high for patients, providers, and health care students. One study by Gros et $\mathrm{al}^{54}$ found that evidence-based psychotherapies, delivered via telehealth, for post-traumatic stress disorder (PTSD) in a veteran population were accepted and valued at the same level as in-person services. Additionally, another recent study providing telepsychology treatment for depression in an older veteran population noted that quality of life and satisfaction with care were not adversely affected by a decision to use telehealth. ${ }^{55}$ Another study reviewed patient satisfaction with telerehabilitation after total knee arthroplasty (TKA). ${ }^{56}$ Two groups were studied, one group received face-to-face home visits and the other participated in home telerehabilitation. Patient satisfaction was measured using the Health Care Satisfaction Questionnaire (HCSQ) and both groups scored equally high with $85 \%$ satisfaction overall. ${ }^{56}$ In a study of 86 men living with Parkinson's disease, participants were provided either the usual in-person care or telehealth. There was an increase in satisfaction for the telehealth modality when asked about overall convenience and accessibility. ${ }^{57}$

Provider satisfaction with telehealth has also been measured in several studies. One study conducted at Veterans Affairs facilities in the northwest US showed that dermatology providers had over $71 \%$ satisfaction with teledermatology ${ }^{58}$ This was measured using a modified patient satisfaction with medical care questionnaire that investigated several domains regarding satisfaction, such as technical quality, efficacy, accessibility, and financial savings; all the domains were viewed as positive. ${ }^{58}$ Satisfaction for providers was also measured at a high level when the use of telehealth was utilized to provide care for poorly controlled type 2 diabetic patients in an urban community health center using an electronic pillbox that was added to a remote home monitoring system. ${ }^{59}$ These are just a few of the examples that can be offered to students to aid in their acceptance of telehealth.

\section{Techniques \\ Multimodal framework for telehealth education}

Educational programs have found it challenging to not only teach telehealth theory but also provide hands-on experiences with technology; this has proven especially difficult within a rapidly changing environment. This article presents a multimodal approach to nurse practitioner telehealth education based on identified learning needs and aligned with nurse competencies and essentials (Figure 2). Based on a review of the literature, four areas of telehealth nursing education are identified: 1) didactic education, 2) experiential simulation, 3 ) projects, and 4) formal clinical telehealth experiences.

\section{Didactic education}

Most of the literature related to the teaching of telehealth is anecdotal. A majority of the university programs that have implemented a telehealth curriculum have utilized a traditional didactic approach, focusing primarily on theory and practical knowledge..$^{8,10,13}$ Specifically, didactic telehealth 


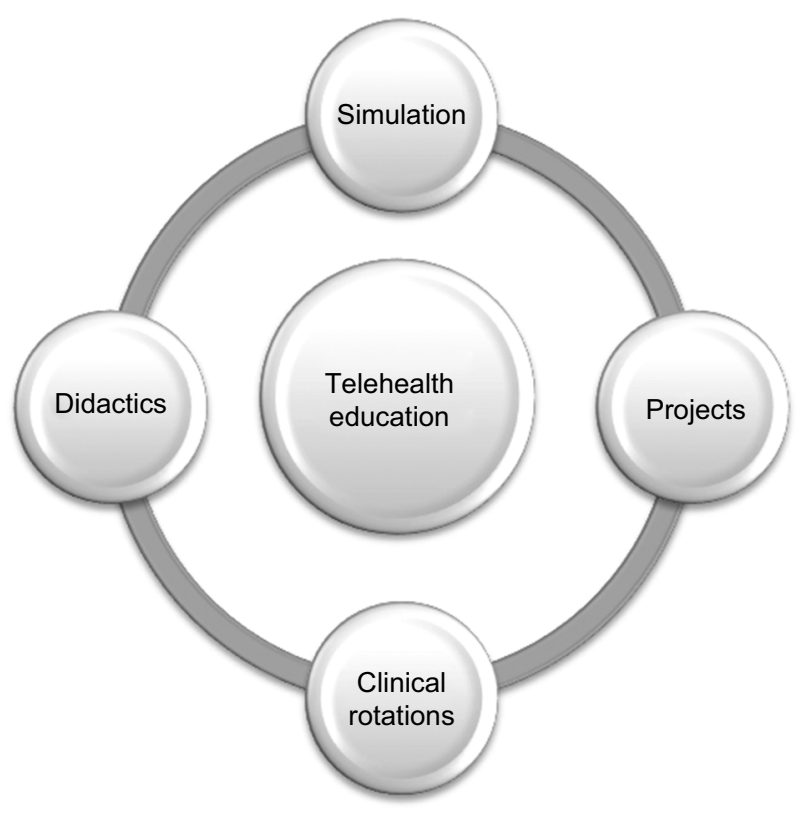

Figure 2 Multimodal approach to telehealth education.

education has been delivered through short online courses, narrated presentations/webinars, videos, and face-to-face lectures. ${ }^{8,10,13,39}$ This is a useful approach for providing for knowledge generations; however, it does not address skill development and comfort with the technology.

\section{Experiential simulation learning}

To overcome resistance to using telehealth, experiential activities become a must. A safe way that programs have found for introducing telehealth is through simulations. Rutledge et $\mathrm{al}^{11}$ developed a telehealth simulation workshop at Old Dominion University for their students using standardized patients. Sixty advanced practice nursing students, in groups of 5-6, conducted an interview of a standardized patient and their caregiver using videoconferencing technology. The patient and caregiver were in one room, and the students were in a second room communicating via computer screens. The students interviewed the patient and caregiver as well as practiced assessment of the patient's stroke condition by having the patient ambulate in front of the screen as well as conduct manual exercises. The students were able to develop comfort with the technology, address telehealth etiquette, and realize that they could actually develop a relationship with the patient over the screen. ${ }^{11}$

Erickson et $\mathrm{al}^{9}$ provided a telehealth demonstration for their nurse practitioner students prior to having them participate in a clinical rotation. The students were connected to the information technology (IT) laboratory at a hospital through videoconferencing technology. They then received instruction on the use of the videoconferencing cameras, digital otoscopes, stethoscopes, and examination cameras. ${ }^{9}$ Other schools have utilized telehealth equipment in the clinical setting to visit with the student or to observe the student conducting an assessment with patients. ${ }^{24,60,61}$ Although the students are not participating in a patient/provider encounter utilizing telehealth equipment, they are afforded the opportunity to use the equipment and practice real-time communication with their instructor.

In another program, students were given an opportunity to work with various pieces of telehealth equipment as they rotated in groups through different work stations. ${ }^{12}$ The goal was to help the students understand how to use telehealth to support a patient at a distance. The first station allowed the students to use telehealth equipment to interview a standardized patient who was recovering from a stroke. In the second station, students were given individual iPads to use to explore websites that stroke patients and their family members could use to obtain relevant information and communicate with professionals. The third station consisted of utilizing electronic health records to obtain static store-and-forward data such as computed tomography (CT) scans and medical records. The fourth station allowed providers to explore some of the clinical decision-making software and mobile applications available to providers and patients related to stroke care and management. $^{12}$

Two of the studies specifically exposed students to telehealth equipment prior to having the students participate in rotations with patients using telehealth. Having the students participate in simulations prior to actually being with patients enhanced their comfort level and skills in using telehealth with actual patients. ${ }^{11,12}$ During a workshop on telehealth delivery using standardized patients, the overwhelming response was positive for their satisfaction with the overall experience. Additionally, they expressed great value for the telehealth modality and its ability to provide care to individuals in a home setting. ${ }^{11}$

\section{Clinical telehealth experience/projects}

Programs have reported success in placing students in clinical settings where they are exposed to the uses of telehealth for patient care. In one program, the students were assigned to participate in an 8-hour clinical rotation at a site that either provided or received telehealth support for patients. ${ }^{11}$ In addition to observing telehealth encounters, the students were expected to complete a project in which they surveyed the providers at the site regarding the reason telehealth was chosen, what patient populations they served, which technologies they utilized, how they accessed the technologies, 
barriers they encountered, and how they overcame the barriers. The students were then expected to develop a plan for implementing telehealth in their own clinical environments. Student placements included a telestroke center, behavior health counseling, emergency room to emergency room, and a rural medical center that sends synchronous and asynchronous data to a tertiary medical center. ${ }^{11}$

A second program implemented a 4-hour clinical experience in which students were paired with preceptors in either an ambulatory or acute care setting that used telehealth to provide care to patients. ${ }^{9}$ Students were allowed to participate by being at the patient site, with the preceptor, or at the college or health system. Students participated by obtaining the patient's history, conducting a review of systems, or conducting a physical examination with the telehealth peripherals such as the examination camera, digital stethoscope, or otoscope. Students were able to access the patient's medical records as well. ${ }^{9}$

Another program focused on provider to provider telehealth encounters by pairing nurse practitioner Doctor of Nursing Practice students and nurse executive Doctor of Nursing Practice students (intraprofessional collaboration). ${ }^{41}$ The pair was responsible for connecting using a technology they had never used before to develop a program to address a specific population need. The students then completed a paper addressing what they learned about each other's role, what technology they used, the benefits and barriers in using the technology, and program they developed. The students were overwhelmingly positive about the experience in using the technology and the opportunity to learn about each other's roles. ${ }^{41}$

Many programs struggle to provide clinical placements that allow students hands-on practical experience due to lack of available resources, student difficulty in traveling to geographically remote sites making them prohibitive for students, and difficulty in scheduling telehealth opportunities. ${ }^{9}$ In addition, student availability does not always match with the provider-patient telehealth encounter. ${ }^{9}$ Other programs have found that minimal faculty exposure, knowledge, and comfort may impact their willingness to offer telehealth educations. ${ }^{15,16}$ For nurse practitioners to be prepared in telehealth training in school, these barriers must be addressed.

\section{Educational programs for practicing providers}

Due to the fact that many health care preprofessional programs do not include formal training related to telehealth within their curricula, many providers are expected to obtain the necessary training for telehealth on the job. Thus, the telehealth training tends to occur in the clinical setting or through postprofessional certification programs. ${ }^{18,24}$

The Telehealth Resource Centers (TRC), a national clearing house for telehealth information related to use, policy, and program development, helps prepare providers for telehealth. ${ }^{50}$ The US has been divided into 14 regional TRCs designed to support each region's efforts related to telehealth (Figure 3). Within each regional resource center, training modules and certification programs exist. Most programs are designed to deliver information through asynchronous modules with hands-on testing at the conclusion of the program. Webinars and teleconferences are also delivered through the TRCs. Most regions also present a yearly conference that allows providers to have an opportunity to network and develop an understanding of the technology that is being developed for the health care arena. ${ }^{50}$

The ATA also provides information and support for health care providers. Information available through the ATA pertains in a large part to program upstart, types of technology and equipment, and policy, laws, and regulations impacting telehealth usage, although they are innovative developers of telehealth practice guidelines. ${ }^{62}$ The ATA is considered a leader within the telehealth arena; however, one must be a member of this organization to take full advantage of their educational offerings. Unfortunately, neither the TRC nor the ATA have specific programs for educating providers on how to utilize telehealth in patient care or to educate providers in the skills necessary to practice in the virtual environment and conduct a successful telehealth visit.

At present, standard competencies required of providers to either successfully run a telehealth program or conduct a telehealth visit have not been established. Some authors have specifically addressed the skill set necessary to conduct a successful visit, but these are currently only recommendations. Clearly, it is paramount that the provider has knowledge of what equipment is available and how to use it. ${ }^{18,63}$ Roles of the telehealth facilitator and interprofessional team members are also essential as there is an originating site and a receiving site that must work seamlessly together. ${ }^{18}$

Even though there are suggestions regarding the knowledge and skills required to provide telehealth, a clear approach to educating the health care workforce has yet to be mandated. Furthermore, telehealth education requirements have yet to be outlined in nurse practitioner education. This often leaves it up to the individual school of nursing, the practitioner, or their employer to decide whether nurse practitioners should pursue training in telehealth and what specific training they should receive. 


\section{TelehealthResourceCenters.org}

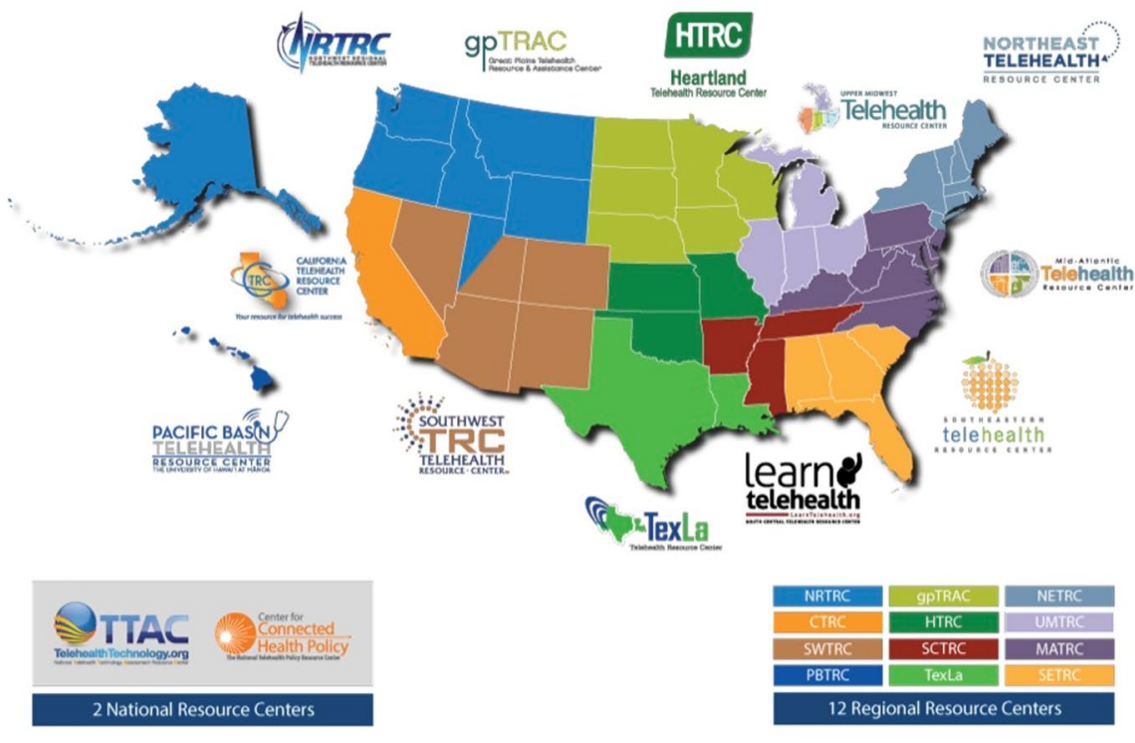

Figure 3 Telehealth Resource Centers in the US and Region Covered.

Note: Reproduced from Center for Connected Health Policy. The National Telehealth Policy Resource Center. The Federally Funded Telehealth Resource Centers. Available From: http:/www.cchpca.org/sites/default/files/resources/PERSPECTIVES\%20ARTICLE\%20CCHP\%20-Federally\%20Funded\%20TRCs\%2020I4.pdf. Accessed May $15,2017.64$

\section{Future directions}

The infusion of telehealth technology into all aspects of health care creates a growing role for nurse practitioners to integrate and utilize telehealth technologies in practice. However, a gap in knowledge exists in preparing providers for telehealth practice due to various factors, the most obvious being the lack of telehealth education in nursing programs. As supported by the literature, a multimodal telehealth education program is recommended in nurse practitioner programs. This would allow for didactic education, telehealth simulation experiences, clinical telehealth rotations with experienced telehealth preceptors, and engagement in telehealth project development. This will provide a well-rounded telehealth educational experience that aligns with professional competencies and essentials of practice.

Nurse practitioners can effectively participate in the transformation of health care through their roles in clinical practice, leadership, scholarship, research, policy, and business practice by participating in telehealth nurse practitioner education and practice. Evidence is mounting to support the positive effect of telehealth on health care and the health care system., ${ }^{2,35}$ Technology allows nurse practitioners to reach patients in a variety of remote settings, expanding the reach of health care providers. Telehealth enables access to care for those who need specialty care or who have difficulty with travel. It improves outcomes through innovative uses of technology to improve frequency and quality of communications and patient engagement. It reduces cost of health care for the facility by improving management of chronic diseases, reducing readmission rates, and improving provider efficiency. Telehealth technologies enable more frequent communication and more frequent physiologic monitoring of patients, reflecting improved outcomes and better utilization of health care resources.

To prepare nurse practitioners for their role as advocates in optimizing health care outcomes, especially in areas where access is limited, they must be trained in the use of telehealth. Programs must prepare students through experiential learning opportunities such as simulation, clinical rotations, and projects as well as didactic sessions. This approach is effective in assisting students to develop the knowledge, skills, and attitudes needed to maximize the use of telehealth and remove barriers to using telehealth in both primary and specialty care.

Specific areas of focus in education must be on partnering with those developing and/or utilizing telehealth technologies to provide students with access to hands-on opportunities. Didactic programs must address the many aspects to telehealth. Finally, competencies must be developed to direct the education and training of nurse practitioners regarding telehealth. 


\section{Conclusion}

Telehealth has forever changed health care. Nurse practitioners educated in telehealth can make strong contributions to nursing and health care as they emerge from programs as future nursing leaders. The issues facing health care and health care resource allocation can be improved with telehealth systems of care developed and implemented by nurse practitioners. It is essential that nurse practitioners become empowered with telehealth knowledge and hands-on skills so that they can be a creative force for innovations in telehealth within practice and health care systems. Schools will be at the forefront of health care as they develop telehealth education programs and prepare to respond to the challenges ahead by promoting innovation through nurse practitioner telehealth education.

\section{Disclosure}

The authors report no conflicts of interest in this work.

\section{References}

1. Gardenier D, Rutledge CM, Gray D. Are nurse practitioners ready for telehealth? J Nurs Pract. 2015;11(9):860-861.

2. Totten A, Womak D, Eden K, et al. Telehealth: mapping the evidence for patient outcomes from systematic reviews. Agency Healthc Res Qual. 2016. June Report no 16-EHC034-EF.

3. Ashhurst EJ, Jones RB, Williamson GR, Emmens T, Perry J. Collaborative learning about e-health for mental health professionals and service users in a structured anonymous online short course: pilot study. $B M C$ Med Educ. 2012;12:37.

4. Ishibashi Y, Jzoji H, Kitano T, Nakajima I. ITU e-Health training program for pacific island community with the support of the Saskawa Peace Foundation. J Med Syst. 2011;35(3):345-351.

5. Jones RB, Maramba I, Boulos MNK, Alexander T. Use of live interactive Webcasting for an international postgraduate module in eHealth: case study evaluation. J Med Internet Res. 2009;11(4):e46.

6. Kobb RF, Lane RJ, Stallings D. E-learning and telehealth: measuring your success. Telemed J E Health. 2008;14(6):576-579.

7. dos Santos AF, Alves HJ, Nogueria JT, Torres RM, Melo Mdo C. Telehealth distance education course in Latin America: analysis of an experience involving 15 countries. Telemed JE Health. 2014;20(8):736-741.

8. Edirippulige S, Smith AC, Armfield NR, Bensink M, Wootin R. Student perceptions of a hands-on practicum to supplement an online eHealth course. J Med Internet Res. 2012;14(6):1-11.

9. Erickson CE, Fauchald S, Ideker M. Integrating telehealth into the graduate nursing curriculum. J Nurs Pract. 2015;11(1):e1-e5.

10. Gallagher-Lepak S, Scheibel P, Gibson C. Integrating telehealth in nursing curricula: can you hear me now. Online J Nurs Inform. 2009;13(2):1-16.

11. Rutledge CM, Haney T, Bordelon M, Renaud M, Fowler C. Telehealth: preparing advanced practice nurses to address healthcare needs in rural and underserved populations. Int J Nurs Educ Scholarsh. 2014;11(1):1-9.

12. Rutledge CM, Renaud M, Shepherd L, et al. Educating advanced practice nurses in using social media in rural healthcare. Int J Nurs Educ Scholarsh. 2011;8(1):1-14.

13. Silva AS, Rizzante FA, Picolini MM, et al. Bauru School of Dentistry Tele-Health League: an educational strategy applied to research, training and extension among applications in telehealth. J Appl Oral Sci. 2011;19(6):599-603.
14. Edirippulige S, Armfield NR. Education and training to support the use of clinical telehealth: a review of the literature. JTelemed Telecare. 2017;23(2):273-282.

15. Ali NS, Carlton KH, Ali OS. Telehealth education in nursing curriculum. Nurse Educ. 2015;40(5):266-269.

16. Zayapragassarazan Z, Kumar S. Awareness, knowledge, attitude and skills of telemedicine among health professional faculty working in teaching hospitals. J Clin Diagn Res. 2016;10(3):JC01-JC04.

17. Haney T, Kott K, Fowler C. Telehealth etiquette in home healthcare: the key to a successful visit. Home Healthc Now. 2015;33(5):254-259.

18. Papanagno D, Sicks S, Hollander JE. Training the next generation of care providers: focus on telehealth. Healthc Transform. 2015:52-63.

19. Hakimnia R, Holmstrom IK, Carlsson M, Hoglund AT. Exploring the communication between telenurse and caller. A critical discourse analysis. Int J Qual Stud Health Well-being. 2014;9:242-255.

20. Hoglund AT, Carlsson M, Holstrom IK, Kaininsky E. Impact of telephone nursing education program for equity in healthcare. Int $J$ Equity Health. 2016;15(152):2-11.

21. Federation of State Medical Boards (FSMB). Model Policy on the Appropriate Use of Telemedicine Technologies in the Practice of Medicine: Report of the State Medical Boards'Appropriate Regulation of Telemedicine (SMART) Workgroup. Available from: http://www.fsmb.org/ Media/Default/PDF/FSMB/Advocacy/FSMB_Telemedicine_Policy. pdf. Accessed March 26, 2017.

22. Conn J [webpage on the Internet]. Newly Approved Telehealth Guideline Causes a Stir. Modern Healthcare. Available from: http:// www.modernhealthcare.com/article/20140428/NEWS/304289931/ newly-approved-telehealth-guideline-causes-a-stir. Accessed March 26, 2017.

23. Bulik R. Human factors in primary care telemedicine encounters. J Telemed Telecare. 2008;14(4):169-172.

24. Sevean P, Dampier S, Spadoni M, Strickland S, Pilatzke S. Bridging the distance: educating nurses for telehealth practice. J Contin Educ Nurs. 2008;39(9):413-418.

25. vanHouwelingen CTM, Moerman AH, Ettema RGA, Kort HSM, Cate O. Competencies required for nursing telehealth activities: a Delphistudy. Nurse Educ Today. 2015;39:50-62.

26. American Telemedicine Association (ATA) [webpage on the Internet]. What Is the Distinction between Telemedicine and Telehealth? Available from: http://www.americantelemed.org/main/about/about-telemedicine/ telemedicine-faqs. Accessed February 8, 2017.

27. Sood SP, Negash S, Mbarika VWA, Kifle M, Prakash N. Differences in public and private sector adoption of telemedicine: Indian case study for sectoral adoption. Stud Health Technol Inform. 2007;130: 257-268.

28. Health Resources and Services Administration (HRSA) [webpage on the Internet]. What Is Telehealth? Available from: https://www.hrsa. gov/healthit/toolbox/RuralHealthITtoolbox/Telehealth/whatistelehealth. html. Accessed February 8, 2017.

29. Schwamm L. Telehealth: seven strategies to successfully implement disruptive technology and transform health care. Health Aff. 2014;33(2):200-206.

30. World Health Organization (WHO). Telemedicine: opportunities and developments in member states. Global Observatory for eHealth Series - Volume 2. Available from: http://www.who.int/goe/publications/ goe_telemedicine_2010.pdf. Accessed February 8, 2017.

31. Raghavendran V, Satish N, Sundari R, Varma S. A literature study on dynamic bandwidth allocation mechanisms for tandem communication networks. J Appl Comput Sci Math. 2014;18(8):13-19.

32. Yesenofski L, Kromer S, Hitchens K. Nurses leading the transformation of patient care through telehealth. J Nurs Adm. 2015;45(12):650-656.

33. Armstrong A, Sanders C, Farbstein A, et al. Evaluation and comparison of store-and-forward teledermatology applications. Telemed JE Health. 2010;16(4):424-438.

34. Rand Corporation [webpage on the Internet]. Paul Baran and the Origins of the Internet. Available from: https://www.rand.org/about/history/ baran.list.html. Accessed February 8, 2017. 
35. Baker L, Scott JJ, Macaulay D, Birnbaum H. Integrated telehealth and care management program for Medicare beneficiaries with chronic disease linked to savings. Health Aff. 2011;30(9):1689-1697.

36. American Telemedicine Association (ATA). State Medicaid Best Practice: Remote Home Monitoring and Home Video Visits. May 2013. Available from: http://dev.americantelemed.org/docs/default-source/ policy/state-medicaid-best-practices-remote-patient-monitoring-andhome-video-visits.pdf?sfvrsn=4. Accessed April 25, 2017.

37. Nagel D, Stacey D, Momtahan K, Gifford W, Doucet S, Etowa J. Getting a picture: a grounded theory of nurses knowing the person in a virtual environment. J Holist Nurs. 2016;20(10):1-19.

38. Demiris G, Krupinski CN, Ben-Arieh D, Washington K, Wu J, Farberow B. The role of human factors in telehealth. Telemed J E Health. 2010;16(4):446-453.

39. LearnTelehealth.org [webpage on the Internet]. Telehealth Etiquette (Video). Arkansas: South Central Telehealth Resource Center. Available from: http://learntelehealth.org/video-items/telehealth-etiquette/. Accessed February 8, 2017.

40. Interprofessional Education Collaborative (IPEC). Core Competencies for Interprofessional Collaborative Practice: 2016 Update. Washington, DC: Interprofessional Education Collaborative (IPEC); 2016.

41. Gray D, Rutledge CM. Using new communication technologies: fostering interprofessional collaboration and telehealth skills in nurse practitioners. J Nurs Pract. 2014;10(10):840-844.

42. Shortridge A, Steinheider B, Ciro C, Randall K, Costner-Lark A, Loving G. Simulating interprofessional geriatric patient care using telehealth: a team-based learning activity. MedEdPORTAL Publ. 2016;12: 10415.

43. American Telemedicine Association (ATA) [homepage on the Internet]. Available from: http://www.americantelemed.org/home. Accessed February 8, 2017.

44. National Council of State Boards of Nursing [webpage on the Internet]. Nurse Licensure Compact. Available from: www.ncsbn.org/nurselicensure-compact.htm. Accessed January 10, 2017

45. Public Health Institute Center for Connected Health Policy [homepage on the Internet]. State Telehealth Policies and Reimbursement Policies Report. Available from: www.cchpca.org. Accessed January 10, 2017.

46. DelliFraine JL, Dansky KH. Home-based telehealth: a review and meta-analysis. J Telemed Telecare. 2008;14(2):62-66.

47. Fisher B, Boothroyd R, Coufal M, et al. Peer support for self-management of diabetes improved outcomes in international settings. Health Aff. 2012;31(1):1130-1139.

48. Klersy C, De Silvestri A, Gabutti G, Regoli F, Auricchino A. A metaanalysis of remote monitoring of heart failure patients. J Am Coll Cardiol. 2009;54(18):1683-1694.

49. Centers for Medicare and Medicaid Services (CMS). National Health Expenditures 2015 Highlights. Available from: https://www.cms.gov/ research-statistics-data-and-systems/statistics-trends-and-reports/nationalhealthexpenddata/downloads/highlights.pdf. Accessed February 8, 2017.
50. Telehealth Resource Centers [webpage on the Internet]. Who Is Your TRC?. National Resource Center. Available from: http://www.telehealthresourcecenter.org/who-your-trc. Accessed February 8, 2017.

51. Mehta S. Telemedicine's potential ethical pitfalls. Virtual Mentor. 2014;16(12):1014-1017.

52. American Medical Association [webpage on the Internet]. American Medicine News: Telemedicine Can Pose Ethical Problems, Delegates Warn. 2012. Available from: http://www.amednews.com/ article/20120702/profession/307029917/7/. Accessed March 14, 2017.

53. Kaplan B, Litewka S. Ethical challenges of telemedicine and telehealth Camb Q Healthc Ethics. 2008;17(4):401-416.

54. Gros DF, Lancaster CL, López CM, Acierno R. Treatment satisfaction of home-based telehealth versus in-person delivery of prolonged exposure for combat-related PTSD in veterans. J Telemed Telecare. Epub 2016 Sep 26.

55. Egede LE, Acierno R, Knapp RG, Walker RJ, Payne EH, Frueh BC. Psychotherapy for depression in older veterans via telemedicine: effect on quality of life, satisfaction, treatment credibility, and service delivery perception. J Clin Psychiatry. 2016;77(12):1704-1711.

56. Moffet H, Tousignant M, Nadeau S, et al. Patient satisfaction with in-home telerehabilitation after total knee arthroplasty: results from a randomized controlled trial. Telemed J E Health. 2017;23(2): 80-87.

57. Wilkinson JR, Spindler M, Wood SM, et al. High patient satisfaction with telehealth in Parkinson disease: a randomized controlled study. Neurol Clin Pract. 2016;6(3):241-251.

58. McFarland LV, Raugi GJ, Reiber GE. Primary care provider and imaging technician satisfaction with a teledermatology project in rural Veterans Health Administration clinics. Telemed J E Health. 2013; 19(11):815-825.

59. Welch G, Balder A, Zagarins S. Telehealth program for type 2 diabetes: usability, satisfaction, and clinical usefulness in an Urban Community Health Center. Telemed J E Health. 2015;21(5):395-403.

60. Loera JA, Kuo YF, Rahr RR. Telehealth distance mentoring of students. Telemed J E Health. 2007;13(1):45-50.

61. Strehle E, Bateman B, Dickinson K. Teaching medical students pediatric cardio vascular examination by telemedicine. Telemed J E Health. 2009;15(4):342-346.

62. Thomas L, Capistrant G [homepage on the Internet]. State Telemedicine Gaps Analysis: Physician Practice Standards and Licensure. American Telemedicine Association. Available from: http://dev.americantelemed. org/docs/default-source/policy/50-state-telemedicine-gaps-analysis-physician-practice-standards-licensure.pdf?sfvrsn=14. Accessed December 19, 2016.

63. Henderson K, Davis TC, Smith M, King M. Nurse practitioners in telehealth: bridging the gaps in healthcare delivery. JNurs Pract. 2014;10(10): $845-850$.

64. Center for Connected Health Policy. The National Telehealth Policy Resource Center. The Federally Funded Telehealth Resource Centers Available From: http://www.cchpca.org/sites/default/files/resources/ PERSPECTIVES\%20ARTICLE\%20CCHP\%20-Federally\%20 Funded\%20TRCs\%202014.pdf. Accessed May 15, 2017.
Advances in Medical Education and Practice

\section{Publish your work in this journal}

Advances in Medical Education and Practice is an international, peerreviewed, open access journal that aims to present and publish research on Medical Education covering medical, dental, nursing and allied health care professional education. The journal covers undergraduate education, postgraduate training and continuing medical education

\section{Dovepress}

including emerging trends and innovative models linking education, research, and health care services. The manuscript management system is completely online and includes a very quick and fair peer-review system. Visit http://www.dovepress.com/testimonials.php to read real quotes from published authors. 